\title{
Improving agricultural economic efficiency in Brazil
}

\author{
Geraldo da Silva e Souza and Eliane Gonçalves Gomes \\ Brazilian Agricultural Research Corporation (Embrapa), SGE, PqEB, W3 Norte final, Asa Norte, Brasília, 70770-901 \\ DF, Brazil \\ E-mail: geraldo.souza@embrap.br [da Silva e Souza]; eliane.gomes@embrapa.br [Gomes]
}

Received 11 March 2013; received in revised form 13 September 2013; accepted 15 September 2013

\begin{abstract}
In this article, we use Brazilian census data (1995/1996 and 2006) to model agricultural production at the state level in Brazil. Cost-efficiency measurements are computed using data envelopment analysis techniques, and the response is assessed via fractional regression. We examine the effects of time, geographic region, education, and investment in agricultural research on economic efficiency. We found that investment in agricultural research and regional dummies have a significant effect on efficiency measurements. On average, South and Southeast states are more efficient than other states. An increase in cost efficiency can be accomplished through investment in agricultural research.
\end{abstract}

Keywords: economic efficiency; DEA frontiers; quasi-maximum likelihood; fractional regression

\section{Introduction}

Brazil is one of the most important countries in terms of agribusiness. In 2011, agribusiness represented about $22 \%$ of Brazilian GDP and $37 \%$ of its exports. The states of the South and Southeast regions, and more recently the Center-west, use more technology, such as improved varieties of plants, fertilizers, irrigation, mechanization, and chemicals. Brazilian agriculture differs regionally because of differences in geographical areas, such as climate and natural resources, and thus production characteristics also differ. For example, in the South region, soybeans, maize, poultry, and pork have particular significance, but in the Northern region, rubber, nuts, and wood extraction are important activities. These regional differences can cause different agricultural performances among regions.

Since there are regional variations in the way agribusiness is organized in Brazil, it can be expected that economic efficiency also differs from state to state. However, some variation can also be expected from other factors, such as education and investment in agricultural research. In this article, we investigate how these two variables affect economic efficiency. This study is useful for managers and decision makers as it examines factors that may cause or influence efficiency. In this sense, it can 
be seen as a decision support tool that can, for instance, identify sectors that need the allocation of resources for improved efficiency.

We use Brazilian agricultural census data (1995/1996 and 2006) to construct a cost frontier based on nonparametric methods. Our approach to the specification of the frontier follows Banker and Natarajan (2004), and is robust relative to cost function specifications. It is not dependent on input prices. Input variables are chosen following the agricultural production models of Binswanger (1974) and Santos (1987). The fractional regression approach proposed by Ramalho et al. (2010) is used to study the impact of covariates on efficiency scores.

Our discussion proceeds as follows. Section 2 is on materials and methods, where we briefly discuss the approaches available for frontier analysis and present our choice of production model and statistical approach. Section 3 discusses agricultural production and the type of data collected from the two censuses. Section 4 provides statistical results. Finally, in Section 5, we summarize the proposed approach and provide some conclusions.

\section{Materials and methods}

Basically two approaches are available in the literature on efficiency analysis: stochastic efficiency frontier analysis and deterministic frontier analysis. In the context of deterministic frontiers, data envelopment analysis (DEA) is by far the most used technique. Owing to the small sample size and our unsuccessful attempts to specify a meaningful parametric response function, our choice was the DEA approach. In our application, the sample comprises the 27 Brazilian states, which are the decision-making units (DMUs), and two time periods representing two consecutive agricultural censuses (1995/1996 and 2006).

DEA can easily deal with multiple outputs and assess economic efficiency without knowledge of factor input prices. This is another reason for its use in this article. Banker and Natarajan (2004) show how these measurements can be computed using only total expenditure data. In this context, if one is interested in the effects of contextual variables, such as education and investment in research in our case, the analysis is carried out in two stages. First, one computes DEA economic efficiency measures from the production model and then relates those to contextual variables via regression procedures. This approach is discussed in detail in Simar and Wilson (2007), Souza and Staub (2007), and Banker and Natarajan (2008). Assuming the exogeneity of the contextual variables, a two-stage analysis is viable, as pointed out in Simar and Wilson (2007), Banker and Natarajan (2008), and Ramalho et al. (2010). The statistical problems in the two-stage approach relate to the cross-sectional correlations induced by the way DEA measures are computed. Simar and Wilson (2007) suggest using the maximum likelihood estimation with bootstrap corrections, whereas Ramalho et al. (2010) suggest using quasi-maximum likelihood (QML) methods in addition to classical techniques, such as the nonlinear least squares and maximum likelihood estimations.

Motivated by these recent results in DEA, we consider the proposal in Ramalho et al. (2010): fractional regression with the QML of Papke and Wooldridge (1996) as the method of estimation. This approach is robust to the presence of cross-sectional correlations. Indeed, Ramalho et al. (2010) propose other alternative models based on what they call two-part models. These latter classes of models do not seem to be compatible with our data, given the small probabilities of efficient units. 
In order to describe the fractional regression approach, let $y$ be the DEA score, $x$ the vector of contextual variables, and $G(\cdot)$ a nonlinear function with values in $[0,1]$. One postulates

$$
E(y \mid x)=G(x \theta) .
$$

The usual choices for $G(\cdot)$ are the logistic (2), $G(x \theta)=\Phi(x \theta)$, where $\Phi(\cdot)$ is the distribution function of the standard normal distribution and $G(x \theta)=1-\exp \{-\exp \{x \theta\}\}$. Indeed, Papke and Wooldridge (1996) suggest the use of any distribution function adequate for binary data:

$$
G(x \theta)=\frac{e^{x \theta}}{1+e^{x \theta}} .
$$

The resulting statistical procedure is named fractional regression by Ramalho et al. (2010). The model specifies the expected value of the performance score as a monotone function of the linear construct $\mu=x \theta$. To estimate $\theta$ from the observations $\left(x_{i}, y_{i}\right) i=1, \ldots, n$, we seek the vector $\hat{\theta}$ maximizing the QML function (3):

$$
L L(\theta)=\sum_{i=1}^{n}\left(y_{i} \log \left(G\left(x_{i} \theta\right)+\left(1-y_{i}\right) \log \left(1-G\left(x_{i} \theta\right)\right)\right)\right) .
$$

Papke and Wooldridge (1996) show that under the correct specification of the mean function $\sqrt{n}(\hat{\theta}-\theta) N(0, V), V$ is estimated using (4). Quoting Ramalho et al. (2010), the "QML estimator is efficient within the class of estimators containing all linear exponential family-based QML and weighted nonlinear least squares estimators." Although not efficient, the parameter $\theta$ may also be estimated by nonlinear least squares:

$$
\begin{aligned}
\hat{V} & =(\hat{A})^{-1} \hat{B} \hat{A} \\
\hat{A} & =\frac{1}{n} \sum_{i=1}^{n} \frac{\hat{g}_{i}^{2}}{\hat{G}_{i}\left(1-\hat{G}_{i}\right)} x_{i}^{\prime} x_{i} \\
\hat{B} & =\frac{1}{n} \sum_{i=1}^{n} \frac{\hat{u}_{i}^{2} \hat{g}_{i}^{2}}{\left(\hat{G}_{i}\left(1-\hat{G}_{i}\right)\right)^{2}} x_{i}^{\prime} x_{i} \\
\hat{G}_{i} & =G\left(x_{i} \hat{\theta}\right), \hat{g}_{i}=G^{\prime}\left(x_{i} \hat{\theta}\right), \hat{u}_{i}=y_{i}-\hat{G}_{i} .
\end{aligned}
$$

Economic efficiency is computed as suggested by Banker and Natarajan (2004). Let $w_{i t}$ denote aggregate agricultural output production for state $i$ in period $t$ and $c_{i t}$ is its total factor input expenditure. Denote by $W_{t}=\left(w_{1 t}, \ldots, w_{N t}\right)$, the output vector for period $t$ and by $C_{t}=\left(c_{1 t}, \ldots, c_{N t}\right)$ the factor input expenditure vector. The economic efficiency of state $i$ in period $t$ is simply the variable returns to scale solution to the one-input one-output DEA problem:

$$
y_{i t}=\min \left\{\theta ; W_{t} \lambda \geq w_{i t}, C_{t} \lambda \leq \theta c_{i t}, \lambda 1=1, \lambda \geq 0\right\} .
$$

\section{Data}

The agricultural variables used to characterize the agricultural production model are the value of agricultural production (including livestock) on the output side and expenditure on five factor 
inputs, following Binswanger (1974) and Santos (1987): land, labor, machinery, fertilizer, and all other inputs.

The data were obtained from the agricultural censuses of 1995/1996 and 2006 (Instituto Brasileiro de Geografia e Estatística, 2009) for each of the 27 Brazilian states. The contextual variables of interest are time dummy (year), regional dummies (Center-west, North, Northeast, South, Southeast), the human development index (HDI) education component (Programa das Nações Unidas para o Desenvolvimento, 2004), and the number of researchers (research) working for Brazilian Agricultural Research Corporation (Embrapa) research centers and Brazilian agricultural state companies, called OEPAs (Organizações Estaduais de Pesquisa Agropecuária). Tables 1 and 2 provide all the data used in the article.

\section{Results and discussion}

Average cost-efficiency statistics are shown in Table 3. We see that the South and Southeast regions are considerably more economically efficient than the other regions.

Ramalho et al. (2010) suggest using Regression Equation Specification Error Tests (RESET), following Pagan and Vella (1989), and $P$ tests for non-nested hypothesis, following Davidson and MacKinnon (1981), for the choice between different functional forms for the mean function. In our particular application, we did not obtain convergence with the Pagan and Vella (1989) approach or with the form of the test presented in Gallant (1987) and Asteriou and Hall (2007). The test of Davidson and MacKinnon (1981) also did not indicate a superior specification. Indeed, the three alternatives considered here (logistic, probit, and $\log -\log$ ) could not be rejected. The $p$-values for the comparisons involved for the pairs (null alternative) logistic versus probit, probit versus logistic, $\log -\log$ versus probit, probit versus $\log -\log , \log -\log$ versus logistic, and logistic versus $\log -\log$ were $0.419,0.491,0.538,0.274,0.530$, and 0.241 , respectively. Further, the three functional forms provided similar fits. This is provided in Table 4 that shows the overall fits for each of them. The best choice seemed to be the log-log specification following the arguments of Asteriou and Hall (2007).

Table 5 shows the statistical results of the QML estimation for fractional regression with the $\log -\log$ specification. We used SAS 9.2 software-Proc Nlmixed (SAS, 2012) for the computation of the QML estimator and Proc IML to estimate the variance-covariance matrix.

The joint test of $\theta=0$ produced a significant chi-square statistic of 40.6 with $8 \mathrm{df}$ ( $p$-value $<$ 0.001). The joint regional effect produced a significant chi-square statistic of 33.1 with $4 \mathrm{df}(p$ value $<0.001)$. The performance suggested by the QML, in an increasing order, was Center-West, Southeast, Northeast, North, and South. The first and last positions are in agreement with Table 3. The marginal tests, however, provided some indication that only Center-West differs significantly from South $(p$-value $=0.077)$. Investment in agricultural research was statistically significant. For each additional 100 researchers hired, we can expect a significant 0.314 increase in economic efficiency, where the effect is computed considering the average value of $\mu=x \theta$ over both censuses. The marginal effect of a variable is given by effect $t_{j}=\theta_{j} \exp (\mu-\exp (\mu))$. Figure 1 depicts the marginal effects for investment in research as a function of $\mu=x \theta$. The maximum response is always obtained when expected cost efficiency is 0 . For the average $\mu=x \theta$, the corresponding expected efficiency was 0.430 for $1995 / 1996$ and 0.639 for 2006, suggesting a significant increase in efficiency over time. 
G. da Silva e Souza and E. Gonçalves Gomes / Intl. Trans. in Op. Res. 22 (2015) 329-337

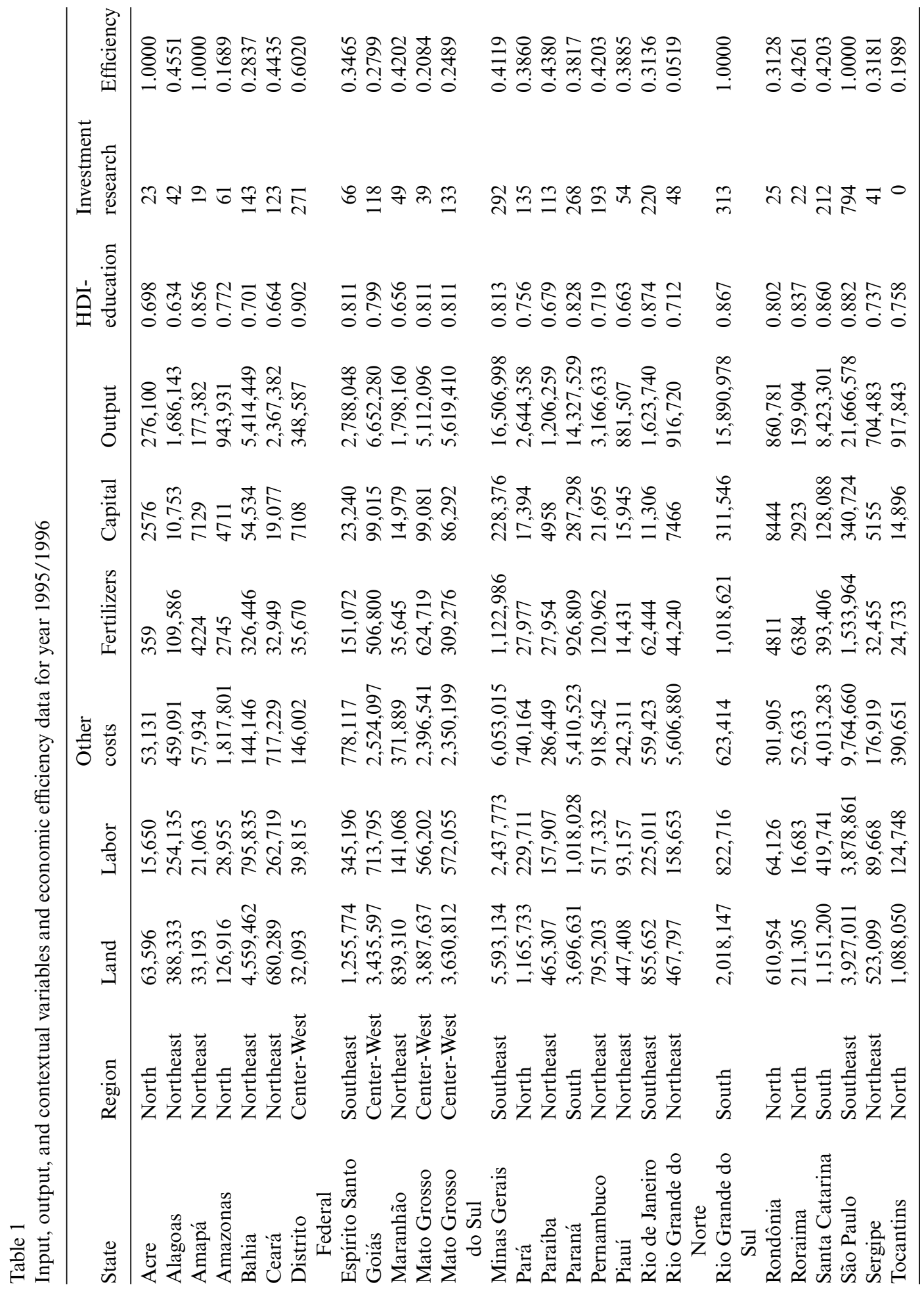

(C) 2013 The Authors. International Transactions in Operational Research (c) 2013 International Federation of Operational Research Societies 


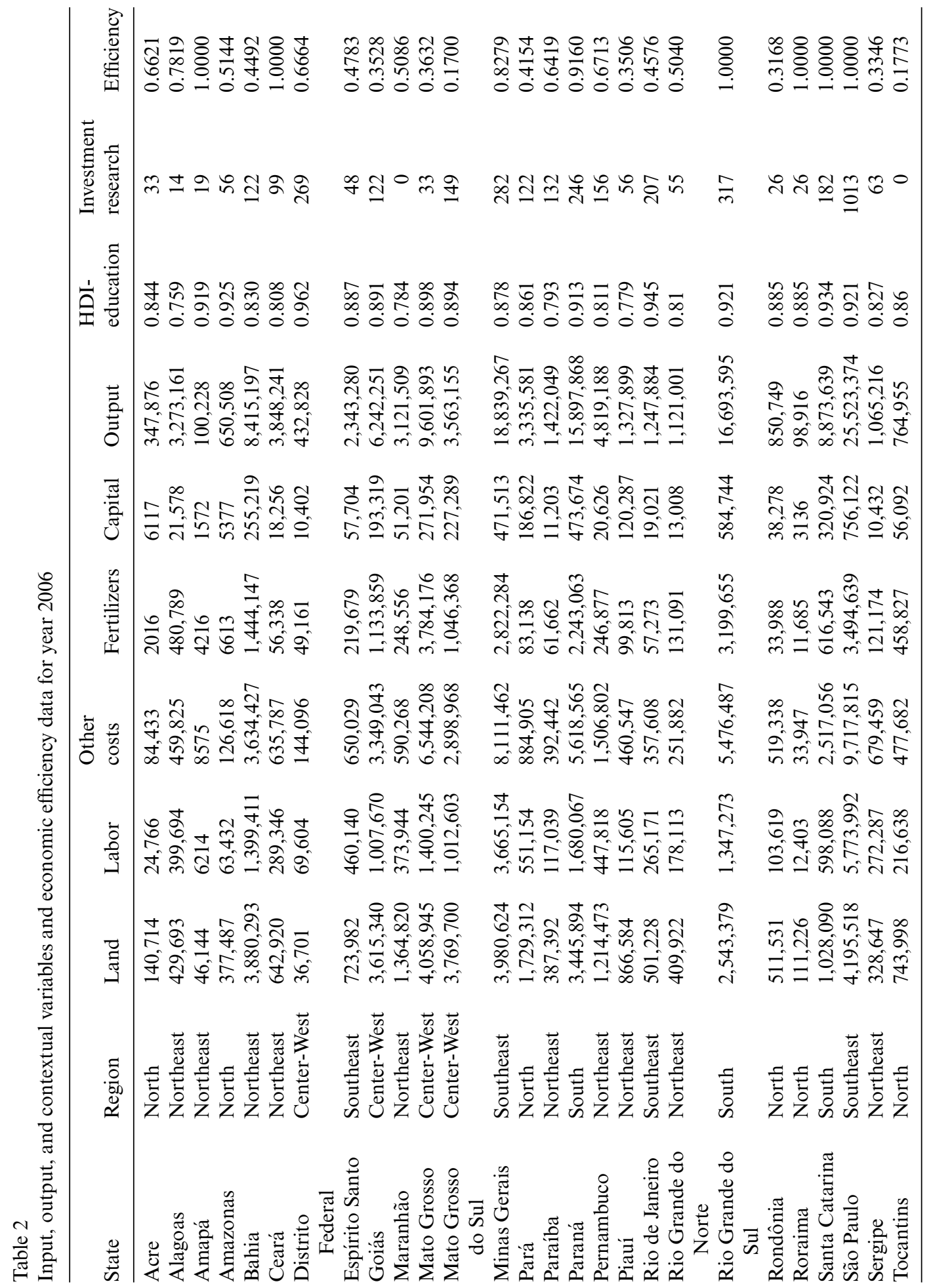

(c) 2013 The Authors.

International Transactions in Operational Research $\odot 2013$ International Federation of Operational Research Societies 
Table 3

Economic (cost) efficiency by regions

\begin{tabular}{llllr}
\hline Region & Mean & Standard error & 95\% confidence interval \\
\hline South & 0.7863 & 0.1227 & 0.5403 & 1.0324 \\
Southeast & 0.6045 & 0.1026 & 0.3988 & 0.8101 \\
North & 0.5413 & 0.0878 & 0.3653 & 0.7173 \\
Northeast & 0.4701 & 0.0488 & 0.3721 & 0.5680 \\
Center-West & 0.3615 & 0.0641 & 0.2328 & 0.4901 \\
\hline
\end{tabular}

Table 4

Fit statistics

\begin{tabular}{llll}
\hline Functional form & $-2 *$ LL & AIC (smaller is better) & BIC (smaller is better) \\
\hline Logistic & 67.3 & 83.3 & 99.2 \\
Log-log & 66.8 & 82.8 & 98.7 \\
Probit & 67.1 & 83.1 & 99.1 \\
\hline
\end{tabular}

AIC, Akaike information criterion; BIC, Bayesian information criterion.

Table 5

Statistical results of the QML estimation for fractional regression with the log-log functional form

\begin{tabular}{lcccc}
\hline Parameter & Coefficient & Standard deviation & $z$ & $p$-Value \\
\hline Constant & -1.325 & 5.547 & 0.239 & 0.811 \\
Research & 0.003 & 0.001 & 2.681 & 0.007 \\
Center-West & -1.003 & 0.567 & 1.770 & 0.323 \\
Northeast & -0.333 & 1.031 & 0.137 & 0.747 \\
North & -0.093 & 0.681 & 1.314 & 0.891 \\
Southeast & -0.722 & 0.550 & 0.134 & 0.189 \\
Education & 0.898 & 6.710 & 0.746 & 0.894 \\
Year & 0.510 & 0.683 & & 0.455 \\
\hline
\end{tabular}

Agricultural research has played an important role in agricultural production and productivity growth as well as overall economic development in the world. In Brazil, high-yielding varieties and other modern technologies released and developed by national agricultural research systems have substantially increased crop and animal yields, the productivity of labor, land, and capital as well as agriculture's diversification and competitiveness in the world market.

Rapid agricultural growth driven by such productivity increases and competitiveness has played a crucial role in Brazil's economic transformation and development process. Both rural and urban populations have benefited from such development either through the direct rural income effect or indirect food price effect on the cost of living. Moreover, opportunities for rural-to-urban migration increase income and thereby the tax revenue of the government that has financed the direct transfer program to the poor.

Our results are in agreement with Gasques et al. (2012), who emphasize the importance of technological factors in agricultural productivity. At the state level, we see that the implication of our study, in terms of the decision-making process, is that production efficiency may be achieved 


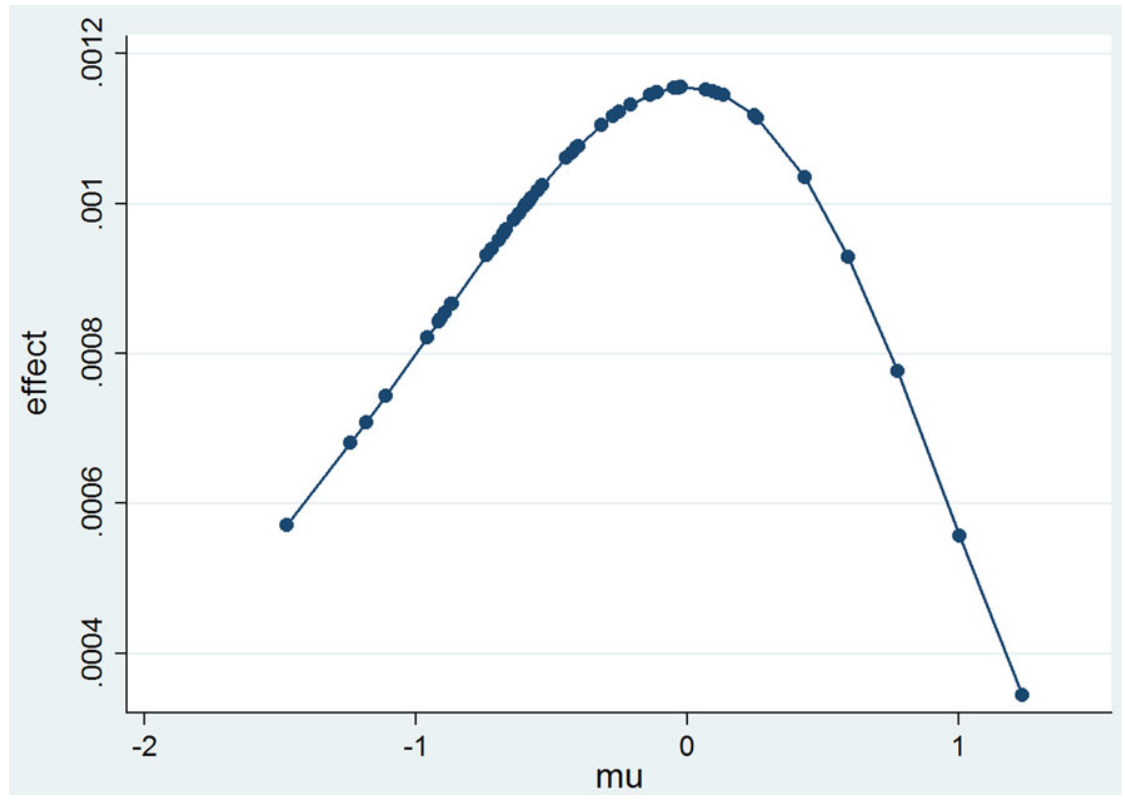

Fig. 1. Marginal effect of research as a function of the linear construct $\mu=x \theta$.

through the incorporation of technology via rural extension. The agricultural census data of 2006 also indicate a strong technical assistance effect on the production frontier (Alves et al., 2012). Effective rural extension is further associated with the number of qualified researchers due to spillover effects.

\section{Summary and conclusions}

We use DEA and Brazilian agricultural census data (1995/1996 and 2006) to assess the effect of contextual variables on cost efficiency. These variables were education and investment in agricultural research. This kind of approach is useful to support decision-making processes, as it can identify factors that may cause or influence efficiency. The production model proposed here uses the value of total agricultural output as the output variable and aggregate expenditure on land, fertilizers, labor, machinery, and other inputs as the input variable.

We conclude that investment in agricultural research and regional dummies have a significant effect on efficiency measurements. Overall, the economic efficiency of the agricultural sector increased (by $39 \%$ ) from 0.442 in 1995/1996 to 0.613 in 2006, whereas HDI-education increased (by 12\%) from 0.774 to 0.868 . Investment in research was stable in the period. Expected efficiency agreed with these data, increasing by 49\% from 0.430 in 1995/1996 to 0.639 in 2006.

South and Southeast states are more efficient than other states on average in the original costefficiency score over censuses. These empirical results suggest that there are significant possibilities to increase cost-efficiency levels in Brazilian agriculture, especially in the Center-West, Northeast, and North regions. Such an increase in efficiency can be accomplished by means of investment in 
agricultural research. The incorporation of technology at the farm level and resulting increase in economic performance are understood as a spillover effect.

\section{References}

Alves, E.R.A., Souza, G.S., Gomes, E.G., Magalhães, E., Rocha, D.P., 2012. Um modelo de produção para a agricultura brasileira e a importância da pesquisa da Embrapa. Revista de Politica Agrícola XII, 35-59.

Asteriou, D., Hall, S.G., 2007. Applied Econometrics: A Modern Approach. Palgrave Macmillan, New York.

Banker, R.D., Natarajan, R., 2004. Statistical tests based on DEA efficiency scores. In Cooper, W.W., Seiford, L.M., Zhu, J. (eds) Handbook on Data Envelopment Analysis. Kluwer International Series, Boston, MA, pp. $299-321$.

Banker, R.D., Natarajan, R., 2008. Evaluating contextual variables affecting productivity using data envelopment analysis. Operations Research 56, 48-58.

Binswanger, H.P., 1974. A cost function approach to the measurement of elasticities of factor demand and elasticities of substitution. American Journal of Agricultural Economics 56, 2, 377-386.

Davidson, R., MacKinnon, J.G., 1981. Several tests for model specification in the presence of alternative hypotheses. Econometrica 49, 3, 781-793.

Gallant, A.R., 1987. Nonlinear Statistical Models. John Wiley and Sons, New York.

Gasques, J., Bastos, E.T., Valdes, C., Bacchi, M., 2012. Produtividade da agricultura brasileira e os efeitos de algumas políticas. Revista de Política Agrícola XXI, 3, 83-92.

Instituto Brasileiro de Geografia e Estatística, 2009. Banco de Dados Agregados. Sistema IBGE de Recuperação Automática-SIDRA. Available at http://www.sidra.ibge.gov.br (accessed 18 November 2009).

Pagan, A., Vella, F., 1989. Diagnostic test for models based on individual data: a survey. Journal of Applied Economics 49, S29-S59.

Papke, L.E., Wooldridge, J.M., 1996. Econometric methods for fractional response variables with an application to 401(k) plan participation rates. Journal of Applied Econometrics 11, 619-632.

Programa das Nações Unidas para o Desenvolvimento, 2004. Desenvolvimento Humano e IDH. Available at http://www.pnud.org.br/idh/ (accessed 18 November 2009).

Ramalho, E.A., Ramalho, J.J.S., Henriques, P.D., 2010. Fractional regression models for second stage DEA efficiency analyses. Journal of Productivity Analysis 34, 239-255.

Santos, R.F., 1987. Presença de Vieses de Mudança Técnica na Agricultura Brasileira. IPE/USP, São Paulo.

SAS, 2012. SAS/STAT ${ }^{\circledR} 12.1$ User's Guide. SAS Institute, Cary, NC.

Simar, L., Wilson, P.W., 2007. Estimation and inference in two-stage: semi-parametric models of production processes. Journal of Econometrics 136, 31-64.

Souza, G.S., Staub, R.B., 2007. Two-stage inference using data envelopment analysis efficiency measurements in univariate production models. International Transactions in Operational Research 14, 245-258.

(C) 2013 The Authors

International Transactions in Operational Research (C) 2013 International Federation of Operational Research Societies 